\title{
ARTICLE
}

\section{Total synthesis of mycobacterial arabinogalactan containing 92 monosaccharide units}

Yong Wu${ }^{1}$, De-Cai Xiong ${ }^{1}$, Si-Cong Chen ${ }^{1}$, Yong-Shi Wang ${ }^{1} \&$ Xin-Shan Ye ${ }^{1}$

Carbohydrates are diverse bio-macromolecules with highly complex structures that are involved in numerous biological processes. Well-defined carbohydrates obtained by chemical synthesis are essential to the understanding of their functions. However, synthesis of carbohydrates is greatly hampered by its insufficient efficiency. So far, assembly of long carbohydrate chains remains one of the most challenging tasks for synthetic chemists. Here we describe a highly efficient assembly of a 92 -mer polysaccharide by the preactivationbased one-pot glycosylation protocol. Several linear and branched oligosaccharide/ polysaccharide fragments ranging from 5-mer to 31-mer in length have been rapidly constructed in one-pot manner, which enables the first total synthesis of a biologically important mycobacterial arabinogalactan through a highly convergent [31+31+30] coupling reaction. Our results show that the preactivation-based one-pot glycosylation protocol may provide access to the construction of long and complicated carbohydrate chains.

\footnotetext{
${ }^{1}$ State Key Laboratory of Natural and Biomimetic Drugs, School of Pharmaceutical Sciences, Peking University, Xue Yuan Road No. 38, Beijing 100191, China. Correspondence and requests for materials should be addressed to X.-S.Y. (email: xinshan@bjmu.edu.cn).
} 
C arbohydrates are involved in many key biological processes, such as cell signaling, cell proliferation and differentiation and viral and bacterial infections, as well as immunoresponse ${ }^{1-3}$. Naturally occurring carbohydrates and glycoconjugates usually exist in microheterogeneous forms, making the isolation of pure carbohydrates and glycoconjugates from natural sources difficult or even impossible in most cases. Therefore, chemical synthesis becomes the main approach to obtain well-defined carbohydrates ${ }^{4-7}$. However, unlike peptides and oligonucleotides, which can be routinely prepared by automated solid-phase synthesizers, the oligosaccharide synthesis is much more difficult. The major challenge for oligosaccharide preparation is the regio- and stereochemistry 8,9 issues in each glycosidic bond formation, making oligosaccharide synthesis a tedious and time-consuming process. Therefore, oligosaccharide synthesis becomes a daunting task, especially when polysaccharides are chosen as the target molecules. Indeed, only a few examples of the synthesis of oligosaccharide sequences containing $>20$ units have been reported over the past few decades ${ }^{10-18}$. These syntheses are challenging because multiple steps of protective group manipulation and intermediate purification are required in most cases.

Arabinogalactan is an essential structural constituent of mycobacterial cell wall, which plays critical roles in the infectivity and pathogenicity of Mycobacterium tuberculosis ${ }^{19}$. Based on experiments and analyses ${ }^{20-22}$, the primary structure of arabinogalactan has been established as a linear galactan composed of about 30 alternating $\beta$ - $(1 \rightarrow 5)$-linked and $\beta$ - $(1 \rightarrow 6)$ linked D-galactofuranose (Galf) residues, to which up to two 22 highly branched arabinan chains (each containing $31 \mathrm{D}$-arabinofuranose (Araf) residues) are attached. The arabinogalactan motifs are useful probes for investigating the biosynthesis of mycobacterial cell wall, especially for characterization of the enzymes that process this polysaccharide, and those enzymes are attractive targets for the development of new antituberculosis drugs $^{23}$. To this end, some solution phase $\mathrm{e}^{14,15,24-27}$ and automated solid-phase ${ }^{28}$ strategies have been developed for the assembly of motifs up to 22 residues, among which the Lowary group ${ }^{14}$ and Ito group ${ }^{15}$ have elegantly synthesized the docosasaccharide arabinan motif via the convergent $[5+5+12]$ and $[7+7+8]$ coupling strategies, respectively. While almost all these syntheses relied upon the stepwise synthesis of oligosaccharide fragments, the object of this study is to achieve the total synthesis of the whole complex polysaccharide rather than the truncated fragments in an efficient way.

In the preactivation-based one-pot glycosylation strategy, several glycosyl donors are allowed to react sequentially in the same vessel regardless of the anomeric reactivities, generating a single oligosaccharide as the main product, which can significantly simplify the synthetic process and increase the overall efficiency ${ }^{29}$. Herein, by utilizing the preactivation-based one-pot glycosylation protocol, we report the first total synthesis of a biologically important mycobacterial arabinogalactan composed of 92 monosaccharide units. Our synthetic strategy involves: (1) several scalable one-pot coupling reactions to generate the linear and branched oligosaccharide fragments, (2) the stereoselective $\beta$-arabinofuranosylation by preactivation protocol, (3) the further one-pot coupling reactions of oligosaccharide fragments for the rapid assembly of polysaccharides up to $31-$ mer, and (4) the convergent $[31+31+30]$ coupling reaction for the final construction of the target polysaccharide.

\section{Results}

Retrosynthetic analysis. The target polysaccharide arabinogalactan 1 was disconnected into two sizeable fragments, that is, the linear Gal $f_{30}$ acceptor 2 and the branched Araf $f_{31}$ donor 3 (Fig. 1). It was conceived that $\mathrm{Gal} f_{30}$ acceptor 2 would be rapidly assembled via a five-component one-pot coupling of several oligosaccharide fragments 4-7. As for the synthesis of Araf $f_{31}$ donor 3, oligosaccharide fragments 10-12 were designed to carry out a four-component one-pot glycosylation reaction. For the preparation of heptasaccharide 10, thioglycoside donors 13a-c and thioglycoside acceptor 14 were planned for the construction of the challenging $\beta$-arabinofuranosyl linkages. Finally, it was expected that all the oligosaccharide fragments $(8,9,15-17)$ would be accessible by the preactivation-based one-pot oligosaccharide synthesis starting from various monosaccharide building blocks. Overall, it was anticipated that the major challenge of our plan towards the total synthesis of arabinogalactan 1 would rely on the efficiency of one-pot glycosylation reactions, especially when large oligosaccharide fragments were attempted as the components in one-pot coupling reactions.

Synthesis of $\mathrm{Gal} f_{30}$ acceptor 2. To test our one-pot strategy for oligosaccharide synthesis, three monosaccharide building blocks 18-20 were designed and synthesized (Supplementary Fig. 1). Using these building blocks, the assembly of hexasaccharide $\mathbf{8}$ in a six-component one-pot manner $(18+19+20+19+20+19)$ by preactivation protocol was tried, which should be rather challenging as up to five glycosidic linkages must be correctly constructed. To our delight, when promoted by stoichiometric $p$-toluenesulfenyl chloride/silver triflate $(p \text {-TolSCl/AgOTf })^{29}$, all glycosylation steps underwent smoothly and none of the side products interfered with the reaction. After optimization of the reaction conditions, hexasaccharide 8 was obtained in $63 \%$ overall yield and on a perfect scale $(1.07 \mathrm{~g})$ within several hours (Fig. $2 \mathrm{a})$. The desilylation of $\mathbf{8}$ provided $\mathbf{5}$ ( $85 \%$ yield), which was re-protected with benzoyl group to give 4 in $96 \%$ yield. Subsequently, the coupling reaction of $\mathbf{8}$ with 1-octanol afforded 21 (91\% yield), which was followed by desilylation to provide 6 in $87 \%$ yield.

With hexasaccharides 4-6 in hand, the further iterative one-pot glycosylation was performed. The five-component one-pot coupling of these oligosaccharides $(\mathbf{4}+\mathbf{5}+\mathbf{5}+\mathbf{5}+\mathbf{6})$ was realized successfully, producing the 30 -mer polysaccharide 22 in $68 \%$ overall yield (Fig. 2 b). It was noteworthy that some deletion sequences were difficult to be removed by column chromatography on silica gel. Gratifyingly, given the difference in molecular weight between the deletion sequences and desired product, size exclusion chromatography was then used to obtain the pure 30-mer polysaccharide 22 (Supplementary Fig. 2). The identity of $\mathbf{2 2}$ was confirmed by its nuclear magnetic resonance (NMR) and matrix-assisted laser desorption/ ionization-time of flight (MALDI-TOF) mass spectra (see Supplementary Information for details). Finally, the global deprotection of 22 via successive debenzoylation and debenzylation provided the 30-mer galactan $23\left([\mathrm{M}+\mathrm{Na}]^{+} \mathrm{m} / z\right.$ calcd. for 5017.4, found: 5018.1).

Having established a highly efficient one-pot approach to the synthesis of polysaccharide up to 30-mer, we turned to accomplish the construction of Gal $f_{30}$ acceptor 2. As shown in Fig. 1, an additional hexasaccharide 9 equipped with two levulinoyl groups was needed. Initially, monosaccharide 24a (Supplementary Fig. 3) was designed as a building block for a six-component one-pot assembly of $\mathbf{9}$. However, the efforts failed due to the migration of levulinoyl group from the $O-5$ to O-6 position. As an alternative route, disaccharide $\mathbf{2 4 b}$ was synthesized (Supplementary Fig. 3). Therefore, a four-component one-pot coupling reaction $(\mathbf{1 8}+\mathbf{2 4 b}+\mathbf{2 4 b}+\mathbf{1 9})$ finally gave the 


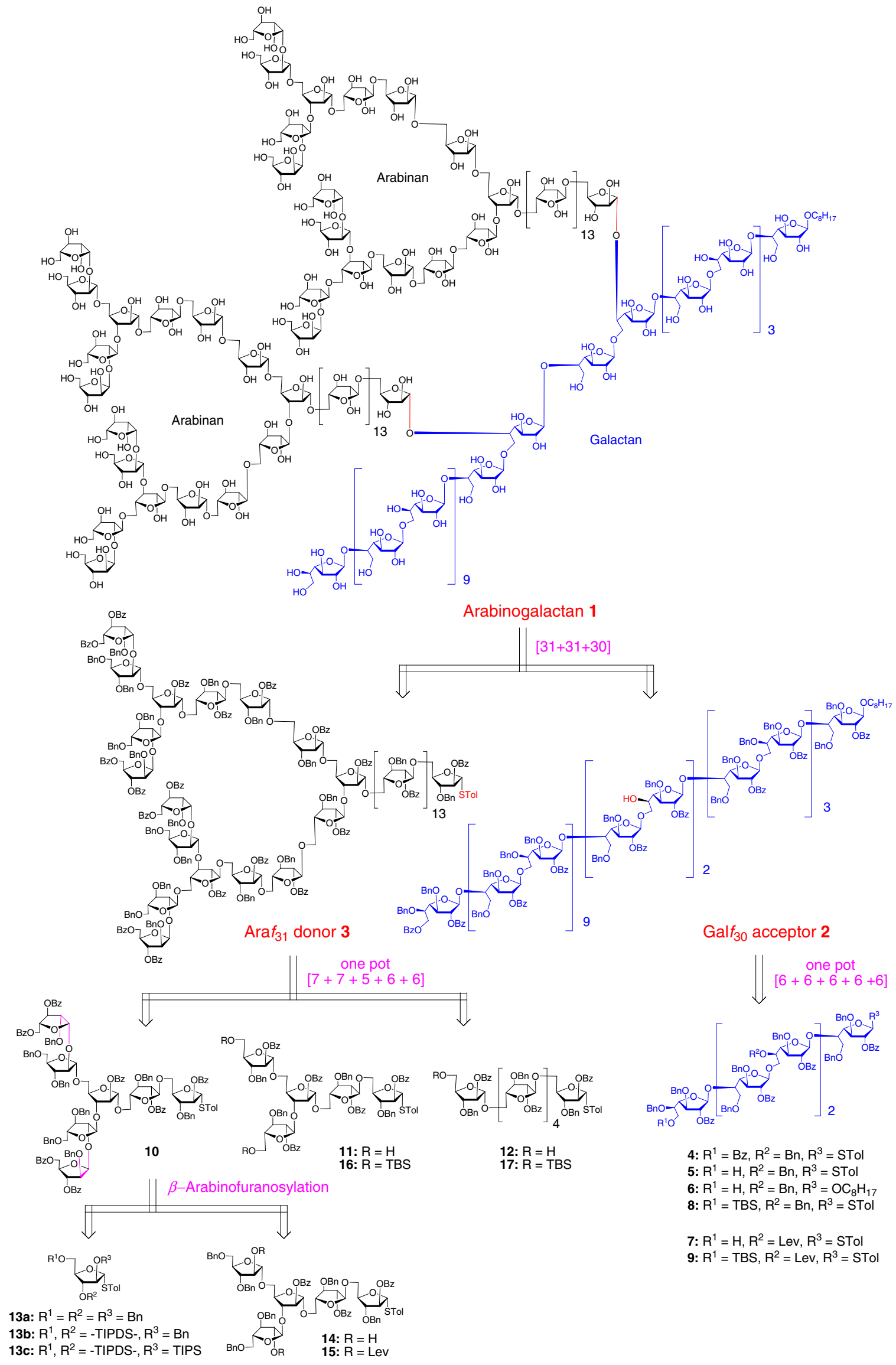

Figure 1 | The structure of mycobacterial arabinogalactan 1 and its retrosynthetic analysis. Bn, benzyl; Bz, benzoyl; Lev, levulinoyl; TBS, tert-butyldimethylsilyl; TIPDS, tetraisopropyldisiloxanylidene; TIPS, triisopropylsilyl; Tol, p-tolyl. 
a

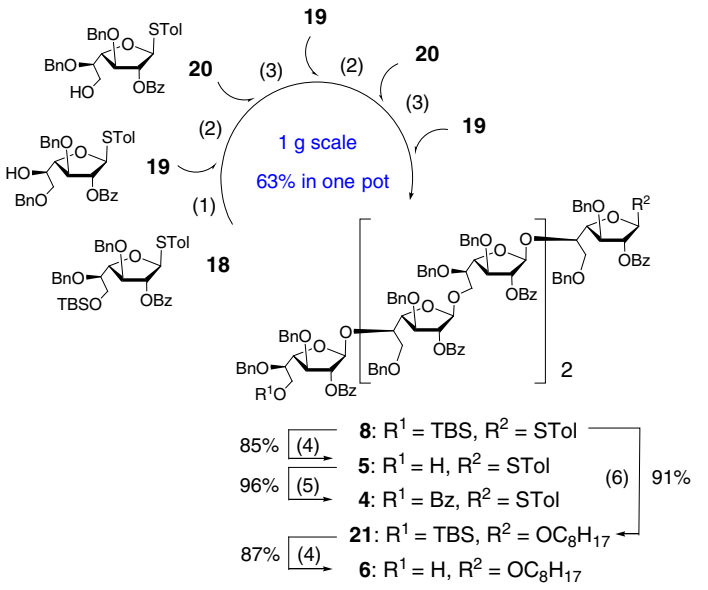

C
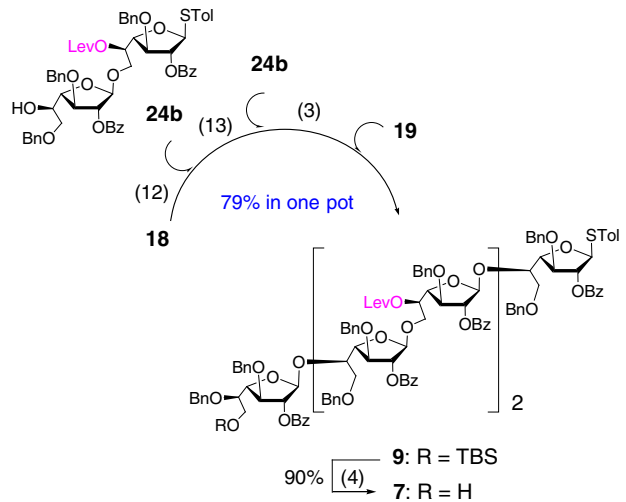

b<smiles>CC1C(C)C(C)C(C)C(C)C(C)C1C</smiles>

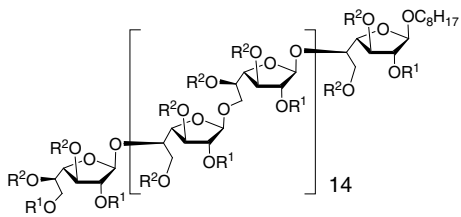

$\begin{aligned} \underset{(10),(11)}{\longrightarrow} & \text { 22: } R^{1}=B z, R^{2}=B \\ \text { 78\%, } 2 \text { steps } & R^{1}=R^{2}=H\end{aligned}$ d

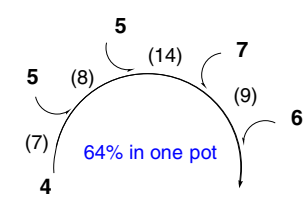

Figure 2 | Synthesis of Galf fo $_{\mathbf{3 0}}$ acceptor 2. (a) Synthesis of oligosaccharides 4-6; (b) Synthesis of 30-mer galactan 23; (c) Synthesis of hexasaccharide 7; (d) Synthesis of Galf $f_{30}$ acceptor 2. Reagents and conditions: (1) TTBP, $4 \AA \mathrm{MS}, \mathrm{CH}_{2} \mathrm{Cl}_{2}, p$ - TolSCl, $\mathrm{AgOTf}$, then 19, $-78^{\circ} \mathrm{C}$ to room temperature; (2) $p$-TolSCl, $\mathrm{AgOTf}$, then $\mathbf{2 0},-78^{\circ} \mathrm{C}$ to room temperature; (3) $\mathrm{p}$-TolSCl, $\mathrm{AgOTf}$, then $\mathbf{1 9},-78^{\circ} \mathrm{C}$ to room temperature; (4) $\mathrm{HF}$-pyridine, $\mathrm{THF} / \mathrm{H}_{2} \mathrm{O}$ (10:1), $35^{\circ} \mathrm{C}$; (5) $\mathrm{Bz}_{2} \mathrm{O}$, DMAP, pyridine, $\mathrm{CH}_{2} \mathrm{Cl}_{2}$, reflux; (6) $p$-TolSCl, AgOTf, TTBP, 1-octanol, $4 \AA \mathrm{MS}, \mathrm{CH}_{2} \mathrm{Cl}_{2},-78^{\circ} \mathrm{C}$; (7) TTBP, $4 \AA \mathrm{MS}, \mathrm{CH}_{2} \mathrm{Cl}_{2}, p$-TolSCl, AgOTf, then $\mathbf{5},-78{ }^{\circ} \mathrm{C}$ to room temperature; (8) $p$-TolSCl, AgOTf, then $\mathbf{5},-78{ }^{\circ} \mathrm{C}$ to room temperature; (9) $p$ - TolSCl, $\mathrm{AgOTf}$, then $\mathbf{6},-78{ }^{\circ} \mathrm{C}$ to room temperature; (10) $\mathrm{NaOCH}_{3}, \mathrm{CH}_{3} \mathrm{OH} / \mathrm{CH}_{2} \mathrm{Cl}_{2}$ (2:1); (11) $\mathrm{Pd} / \mathrm{C}, \mathrm{H}_{2}$, EtOAc/THF/1-PrOH/ $\mathrm{H}_{2} \mathrm{O}$ (2:1:1:1); (12) TTBP, $4 \AA \mathrm{MS}, \mathrm{CH} \mathrm{Cl}_{2}, p-\mathrm{TolSCl}, \mathrm{AgOTf}$,

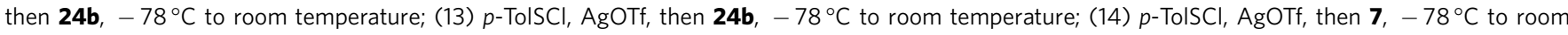
temperature; (15) $\mathrm{H}_{2} \mathrm{NNH}_{2}-\mathrm{AcOH}, \mathrm{THF} / \mathrm{CH}_{3} \mathrm{OH}$ (10:1). DMAP, 4,4-dimethylaminopyridine; MS, molecular sieves; TTBP, 2,4,6-tri-tert-butylpyrimidine.

desired hexasaccharide 9 in $79 \%$ yield (Fig. 2c), which was subjected to desilylation to afford 7 ( $90 \%$ yield). Subsequently, polysaccharide $\mathbf{2 5}$ was assembled in a five-component one-pot manner as described in the construction of 22 by coupling the oligosaccharide fragments $(4+5+5+7+6)$ in $64 \%$ overall yield (Fig. 2d). Exposure of 25 to hydrazine acetate successfully fulfilled the preparation of the desired Gal $f_{30}$ acceptor 2 (85\% yield).

Synthesis of Araf $f_{31}$ donor 3. The assembly of the branched $\mathrm{Araf}_{31}$ donor 3 required three oligosaccharide intermediates, that is, $\beta$-Araf-containing heptasaccharide 10, branched pentasaccharide 11 and linear hexasaccharide 12. For this purpose, a set of arabinofuranosyl building blocks (13a-c, 26-29) were designed and synthesized (Supplementary Fig. 4). A six-component iterative one-pot glycosylation of monosaccharides 26 and $27(26+27+27+27+27+27)$ afforded hexasaccharide 17 in excellent yield (73\%) and on gram scale $(1.20 \mathrm{~g})$ (Fig. 3a). The desilylation of $\mathbf{1 7}$ resulted in the desired hexasaccharide 12 (92\% yield). Likewise, the one-pot coupling reaction of building blocks 26,28 (ref. 30) and 27 provided a branched pentasaccharide 16 very smoothly (78\% yield), which was further converted into diol $\mathbf{1 1}$ by desilylation in $95 \%$ yield (Fig. 3b). For the preparation of heptasaccharide 10, another diol
14 was required. Initially, the glycosyl donor 29a (ref. 31) with chloroacetyl group at the $\mathrm{O}-2$ position was chosen for the one-pot construction of pentasaccharide 15a (Supplementary Table 1), but the overall yield was moderate $(43 \%)$. Fortunately, when the donor 29 equipped with a levulinoyl group was employed for the one-pot glycosylation reaction, pentasaccharide 15 was rapidly assembled in $76 \%$ overall yield (Fig. 3b). Ultimately, deacylation of 15 gave diol 14 (94\% yield).

Our attention was then turned to the synthesis of heptasaccharide 10, which involved the stereocontrolled installation of two challenging $\beta$-arabinofuranosyl linkages. Among a number of innovative glycosyl donors developed by several groups ${ }^{25,31-37}$, perbenzyl-protected thioglycoside 13a (ref. 25) and 3,5-O-tetraiso propyldisiloxanylidene-protected thioglycosides 13b,c (ref. 31) were synthesized for the current purpose (Supplementary Table 2). Although these donors proved useful for direct $\beta$-arabinofuranosylation, whether they could be subjected to thioglycoside acceptor 14 under the donor-preactivation conditions $^{38}$ remained to be explored. After some optimization, the best result arised when 4.0 equiv. of $\mathbf{1 3 b}$ was preactivated by $p$-TolSCl/AgOTf and subsequently glycosylated with 1.0 equiv. of diol 14, delivering heptasaccharide 30b with good stereoselectivity $(\beta, \beta$-isomer/other isomers $=9 / 1)$. Removal of the silyl groups in $\mathbf{3 0 b}$ afforded $\mathbf{3 1}$ (74\% over two steps, Fig. 3c), in which the newly formed $\beta$-arabinofuranosyl linkages were 
a

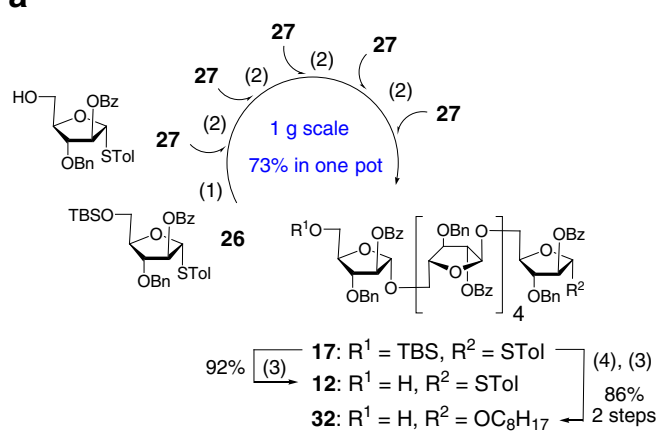

b

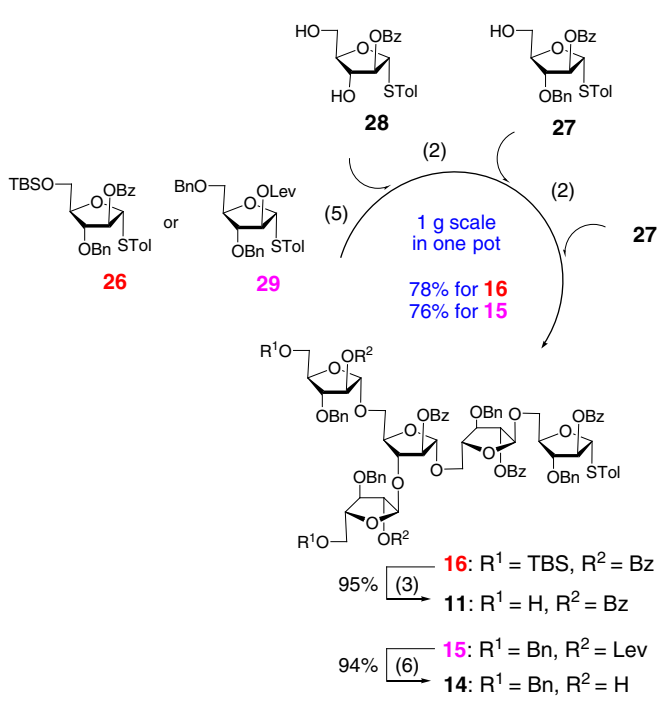

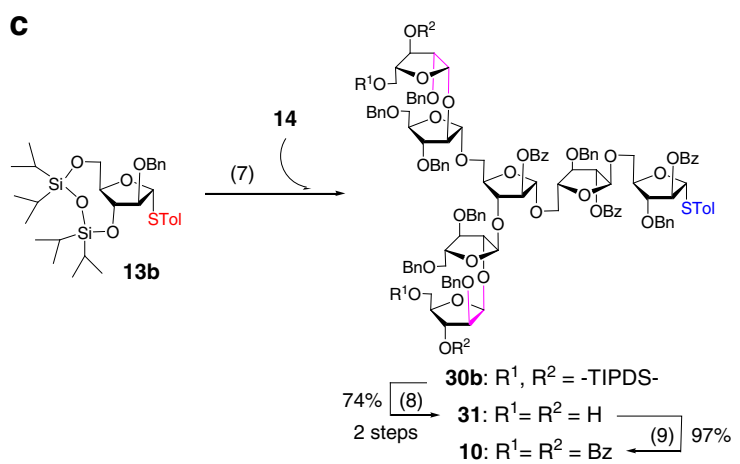

d

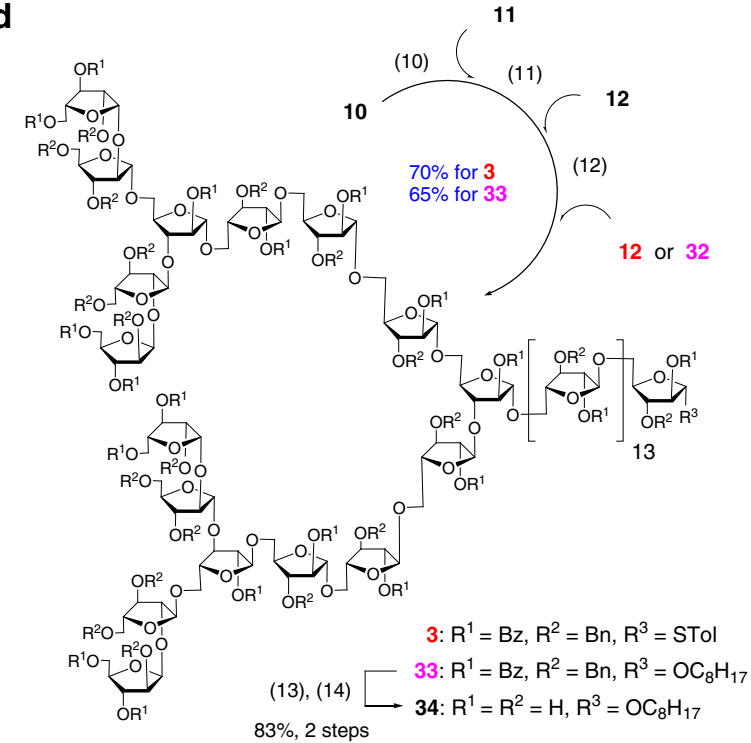

Figure 3 | Synthesis of Araf $_{\mathbf{3 1}}$ donor 3. (a) Synthesis of oligosaccharides 12 and 32; (b) Synthesis of diols $\mathbf{1 1}$ and 14; (c) Synthesis of heptasaccharide 10; (d) Synthesis of $\mathrm{Araf}_{31}$ donor $\mathbf{3}$ and 31-mer arabinan 34. Reagents and conditions: (1) TTBP, $4 \AA \mathrm{MS}, \mathrm{CH}_{2} \mathrm{Cl}_{2}, \mathrm{p}-\mathrm{TolSCl}_{1} \mathrm{AgOTf}$, then 27, $-78{ }^{\circ} \mathrm{C}$ to room temperature; (2) $p$-TolSCl, AgOTf, then $\mathbf{2 7},-78^{\circ} \mathrm{C}$ to room temperature; (3) TBAF, AcOH, THF; (4) $p$-TolSCl, $\mathrm{AgOTf}, \mathrm{TTBP}, 1-\mathrm{octanol}, 4 \AA \mathrm{MS}, \mathrm{CH} \mathrm{Cl}_{2}$ $-78^{\circ} \mathrm{C}$; (5) TTBP, $4 \AA \mathrm{MS}, \mathrm{CH}_{2} \mathrm{Cl}_{2}, p$-TolSCl, AgOTf, then 28 , $-78^{\circ} \mathrm{C}$ to room temperature; (6) $\mathrm{H}_{2} \mathrm{NNH}_{2}-\mathrm{AcOH}, \mathrm{THF} / \mathrm{CH} \mathrm{H}_{3} \mathrm{OH}$ (10:1); (7) p-TolSCl, AgOTf, then 14, $-78^{\circ} \mathrm{C}$; (8) TBAF, THF; (9) $\mathrm{Bz}_{2} \mathrm{O}$, DMAP, pyridine, $\mathrm{CH}_{2} \mathrm{Cl}_{2}$, reflux; (10) TTBP, $4 \AA \mathrm{MS}, \mathrm{CH}_{2} \mathrm{Cl}_{2}, p-\mathrm{TolSCl}, \mathrm{AgOTf}$, then $11,-78^{\circ} \mathrm{C}$ to room temperature; (11) $p$-TolSCl, $\mathrm{AgOTf}$, then 12, $-78^{\circ} \mathrm{C}$ to room temperature; (12) $p$-TolSCl, AgOTf, then $\mathbf{1 2}$ or $\mathbf{3 2},-78^{\circ} \mathrm{C}$ to room temperature; $(13) \mathrm{NaOCH}_{3}$ $\mathrm{CH}_{3} \mathrm{OH} / \mathrm{CH}_{2} \mathrm{Cl}_{2}$ (2:1); (14) $\mathrm{Pd} / \mathrm{C}, \mathrm{H}_{2}$, EtOAc/THF/1-PrOH/ $\mathrm{H}_{2} \mathrm{O}$ (2:1:1:1). TBAF, tetra-n-butylammonium fluoride.

confirmed by the ${ }^{13} \mathrm{C}$ NMR spectrum (appearance at 99.6 and 99.1 p.p.m.) $)^{39}$. Finally, the re-protection of 31 with benzoyl groups yielded the desired heptasaccharide 10 (97\% yield).

With oligosaccharide building blocks 10-12 in hand, the assembly of $\mathrm{Araf}_{31}$ donor 3 by preactivation-based one-pot glycosylation protocol was attempted. This one-pot reaction was expected to be more challenging due to the steric hindrance in the double glycosylation of $\operatorname{Ara} f_{5}$ acceptor 11 using $\operatorname{Araf}_{7}$ donor 10. Surprisingly, the reaction proceeded smoothly when 2.3 equiv. of $\mathbf{1 0}$ was reacted with 1.0 equiv. of $\mathbf{1 1}$, delivering an $\operatorname{Araf}_{19}$ intermediate, which was sequentially coupled with two Ara $f_{6}$ acceptors 12 in a single flask without any intermediate isolation to afford the $\mathrm{Araf}_{31}$ donor $\mathbf{3}$ in $70 \%$ overall yield (Fig. 3d). To further confirm the identity of this 31-mer polysaccharide, an $\operatorname{Araf}_{6}$ acceptor 32 bearing an alkyl group at the reducing end was synthesized (Fig. 3a). Thus a fourcomponent one-pot coupling reaction of oligosaccharides 10-12 and 32 gave a similar 31-mer polysaccharide 33 in $65 \%$ yield (Fig. 3d), which was fully deprotected via deacylation and hydrogenolysis to afford the arabinan $34\left([\mathrm{M}+\mathrm{Na}]^{+}\right.$ monoisotopic $\mathrm{m} / \mathrm{z}$ calcd. for 4246.4 , found: 4246.3 ; $[\mathrm{M}+\mathrm{K}]^{+}$ monoisotopic $m / z$ calcd. for 4262.4 , found: 4262.2$)$. Gratifyingly, the ${ }^{1} \mathrm{H}$ and ${ }^{13} \mathrm{C}$ NMR data of 34 were found to be identical with previous reports ${ }^{14,40}$ except for the differences in some repeating units.

Assembly of arabinogalactan 1. Our final task was the glycosylation of Gal $f_{30}$ acceptor 2 with $\operatorname{Araf}_{31}$ donor 3 to finish the assembly of target polysaccharide. To the best of our knowledge, no glycosylation reactions between polysaccharide sequences composed of $>20$ units were reported to date. For the planned $[31+31+30]$ coupling reaction, it was anticipated that the biggest challenge would come from the steric hindrance by the bulky size of both the donor and acceptor, especially when a double glycosylation was required. Indeed, when a wide variety of promoter systems such as $p$-TolSCl/AgOTf ${ }^{29}$, NIS/AgOTf ${ }^{41}$, NIS/TfOH ${ }^{42}, \quad N$-( $p$-methylphenylthio)- $\varepsilon$-caprolactam/ $/ \mathrm{Tf}_{2} \mathrm{O}^{43}, \mathrm{TBPA}^{44}, \mathrm{Ph}_{3} \mathrm{Bi}(\mathrm{OTf})_{2}$ (ref. 45), BSP/Tf $\mathrm{O}^{46}$ and $\mathrm{Ph}_{2} \mathrm{SO} / \mathrm{Tf}_{2} \mathrm{O}^{47}$ were examined (Supplementary Table 3), no double glycosylation product or only some monoglycosylation product was observed before the donor decomposed, prompting us to further screen the reaction conditions. Encouragingly, it was found that benzenesulfinyl morpholine/triflic anhydride (BSM/ $\left.\mathrm{Tf}_{2} \mathrm{O}\right)^{48}$ developed by our group is the most effective promoter. And indeed, when promoted by $\mathrm{BSM} / \mathrm{Tf}_{2} \mathrm{O}$, this double 


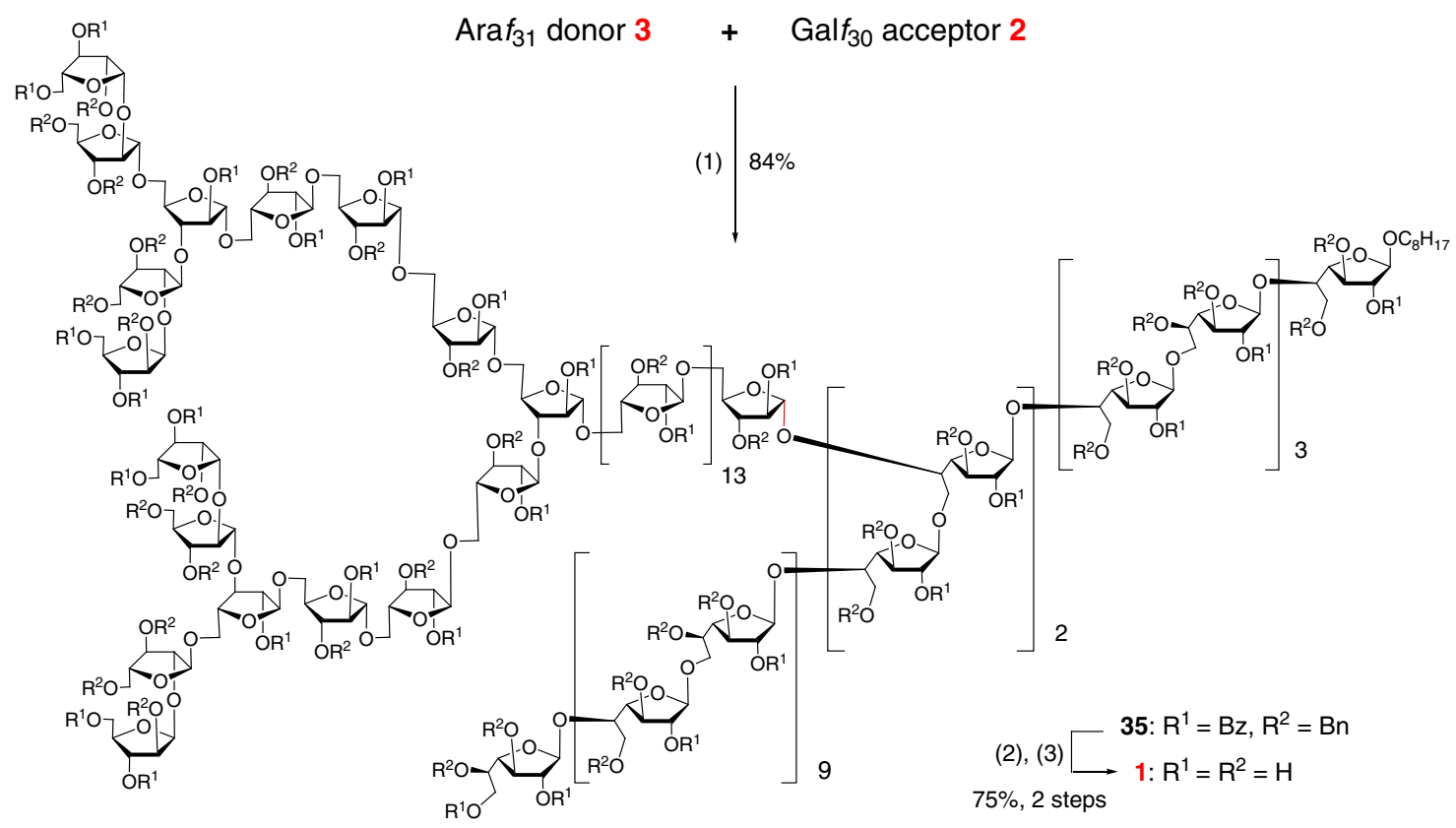

Figure 4 | Assembly of arabinogalactan 1. Reagents and conditions: (1) $\mathrm{BSM}, \mathrm{Tf}_{2} \mathrm{O}, 4 \AA \mathrm{MS}, \mathrm{CH}_{2} \mathrm{Cl}_{2},-40^{\circ} \mathrm{C}$; (2) $\mathrm{NaOCH}, \mathrm{CH}_{3} \mathrm{OH} / \mathrm{THF}(2: 1)$; (3) $\mathrm{Pd} / \mathrm{C}, \mathrm{H}_{2}, \mathrm{EtOAc} / \mathrm{THF} / 1-\mathrm{PrOH} / \mathrm{H}_{2} \mathrm{O}$ (2:1:1:1). BSM, benzenesulfinyl morpholine.

glycosylation was extremely clean and complete (indicated by thin-layer chromatography analysis), delivering the fully protected arabinogalactan 35 in $84 \%$ yield (Fig. 4). Although signals of the anomeric protons in ${ }^{1} \mathrm{H}$ NMR spectrum were obscured due to the extensive overlapping, the anomeric carbons were distinctive in ${ }^{13} \mathrm{C}$ NMR spectrum (all anomeric carbons of $\alpha$-Ara $f$ residues and $\beta$-Gal $f$ residues were between 105 and 107 p.p.m., and anomeric carbons of $\beta$-Araf residues appeared at 101.0 and 100.6 p.p.m.). The identity of 35 was further supported by its MALDI-TOF mass spectrum $\left([\mathrm{M}+\mathrm{Na}]^{+} \mathrm{m} / z\right.$ calcd. for 33885.4 , found: 33884.7 ). Finally, the global deprotection of 35 by the successive deacylation and hydrogenolysis was conducted, affording the target polysaccharide arabinogalactan $\mathbf{1}$ successfully.

\section{Discussion}

We have developed a concise and highly efficient strategy for the first total synthesis of 92-mer mycobacterial arabinogalactan $\mathbf{1}$. This work not only represents the longest well-defined carbohydrate chain synthesis up to date, but also provides useful compounds as probes for further investigations on mycobacterial cell wall-related biological events. Our synthetic strategy highlights a series of efficient preactivation-based one-pot glycosylation reactions to minimize the synthetic steps, the stereoselective $\beta$-arabinofuranosylation by preactivation protocol and the convergent $[31+31+30]$ double glycosylation reaction, thus offering a straightforward access to the target polysaccharide. Our work may open an avenue to the synthesis of complex polysaccharides with biological importance that are either difficult or impossible to access through isolation or semisynthesis.

\section{Methods}

General. The complete experimental details and compound characterization data can be found in Supplementary Methods. For the NMR, HPLC and MALDI-TOF mass spectra of the compounds in this article, see Supplementary Figs 5-126.

General procedure for preactivation-based one-pot glycosylation reaction A mixture of glycosyl donor, TTBP and freshly activated $4 \AA$ molecular sieves in anhydrous $\mathrm{CH}_{2} \mathrm{Cl}_{2}$ under argon atmosphere was stirred for $20 \mathrm{~min}$ at room temperature and cooled to $-78^{\circ} \mathrm{C}$. After $5 \mathrm{~min}$, stoichiometric amount of p-TolSCl was added to the mixture, followed by the addition of AgOTf. After another $5 \mathrm{~min}$, a solution of glycosyl acceptor in anhydrous $\mathrm{CH}_{2} \mathrm{Cl}_{2}$ was slowly added. The resulting mixture was slowly warmed to room temperature within $2 \mathrm{~h}$, stirred for another $20 \mathrm{~min}$ and cooled back to $-78^{\circ} \mathrm{C}$. The glycosylation operation mentioned above was repeated until the generation of the desired product.

Data availability. The authors declare that the data supporting the findings of this study are available within the article and its Supplementary Information files. And all data are available from the authors upon reasonable request.

\section{References}

1. Varki, A. Biological roles of oligosaccharides: all of the theories are correct. Glycobiology 3, 97-130 (1993).

2. Bertozzi, C. R. \& Kiessling, L. L. Chemical glycobiology. Science 291, 2357-2364 (2001).

3. Boltje, T. J., Buskas, T. \& Boons, G.-J. Opportunities and challenges in synthetic oligosaccharide and glycoconjugate research. Nat. Chem. 1, 611-622 (2009).

4. Danishefsky, S. J., McClure, K. F., Randolph, J. T. \& Ruggeri, R. B. A strategy for the solid-phase synthesis of oligosaccharides. Science 260, 1307-1309 (1993).

5. Yamada, H., Harada, T., Miyazaki, H. \& Takahashi, T. One-pot sequential glycosylation: a new method for the synthesis of oligosaccharides. Tetrahedron Lett. 35, 3979-3982 (1994).

6. Zhang, Z. et al. Programmable one-pot oligosaccharide synthesis. J. Am. Chem Soc. 121, 734-753 (1999).

7. Plante, O. J., Palmacci, E. R. \& Seeberger, P. H. Automated solid-phase synthesis of oligosaccharides. Science 291, 1523-1527 (2001).

8. Nigudkar, S. S. \& Demchenko, A. V. Stereocontrolled 1,2-cis glycosylation as the driving force of progress in synthetic carbohydrate chemistry. Chem. Sci. 6, 2687-2704 (2015).

9. Wang, C.-C. et al. Regioselective one-pot protection of carbohydrates. Nature 446, 896-899 (2007).

10. Matsuzaki, Y., Ito, Y., Nakahara, Y. \& Ogawa, T. Synthesis of branched poly- $N$-acetyl-lactosamine type pentaantennary pentacosasaccharide: glycan part of a glycosyl ceramide from rabbit erythrocyte membrane. Tetrahedron Lett. 34, 1061-1064 (1993).

11. Pozsgay, V. A new strategy in oligosaccharide synthesis using lipophilic protecting groups: synthesis of a tetracosasaccharide. Tetrahedron: Asymmetry 11, 151-172 (2000).

12. Fraser-Reid, B., Lu, J., Jayaprakash, K. N. \& López, J. C. Synthesis of a 28-mer oligosaccharide core of Mycobacterial lipoarabinomannan (LAM) requires only two $n$-pentenyl orthoester progenitors. Tetrahedron: Asymmetry 17, 2449-2463 (2006). 
13. Cheon, H.-S., Lian, Y. \& Kishi, Y. Highly stereoselective and iterative synthesis of $\alpha$-(1 $\rightarrow 4)$-linked polysaccharides composed of 3-O-methyl-D-mannose. Org. Lett. 9, 3323-3326 (2007).

14. Joe, M., Bai, Y., Nacario, R. C. \& Lowary, T. L. Synthesis of the docosanasaccharide arabinan domain of mycobacterial arabinogalactan and a proposed octadecasaccharide biosynthetic precursor. J. Am. Chem. Soc. 129, 9885-9901 (2007).

15. Ishiwata, A. \& Ito, Y. Synthesis of docosasaccharide arabinan motif of mycobacterial cell wall. J. Am. Chem. Soc. 133, 2275-2291 (2011).

16. Calin, O., Eller, S. \& Seeberger, P. H. Automated polysaccharide synthesis: assembly of a 30mer mannoside. Angew. Chem. Int. Ed. 52, 5862-5865 (2013).

17. Hansen, S. U., Miller, G. J., Cliff, M. J., Jayson, G. C. \& Gardiner, J. M. Making the longest sugars: a chemical synthesis of heparin-related $[4]_{\mathrm{n}}$ oligosaccharides from 16-mer to 40-mer. Chem. Sci. 6, 6158-6164 (2015).

18. Islam, M., Shinde, G. P. \& Hotha, S. Expedient synthesis of the heneicosasaccharyl mannose capped arabinomannan of the Mycobacterium tuberculosis cellular envelope by glycosyl carbonate donors. Chem. Sci. doi:10.1039/C6SC04866H (2017).

19. Brennan, P. J. Structure, function, and biogenesis of the cell wall of Mycobacterium tuberculosis. Tuberculosis 83, 91-97 (2003).

20. Alderwick, L. J. et al. Deletion of Cg-emb in corynebacterianeae leads to a novel truncated cell wall arabinogalactan, whereas inactivation of $\mathrm{Cg}$ - $u b i \mathrm{~A}$ results in an arabinan-deficient mutant with a cell wall galactan core. J. Biol. Chem. 280, 32362-32371 (2005)

21. Bhamidi, S. et al. The identification and location of succinyl residues and the characterization of the interior arabinan region allow for a model of the complete primary structure of Mycobacterium tuberculosis mycolyl arabinogalactan. J. Biol. Chem. 283, 12992-13000 (2008).

22. Bhamidi, S. et al. Detailed structural and quantitative analysis reveals the spatial organization of the cell walls of in Vivo grown Mycobacterium leprae and in vitro grown Mycobacterium tuberculosis. J. Biol. Chem. 286, 23168-23177 (2011).

23. Lowary, T. L. Twenty years of mycobacterial glycans: furanosides and beyond. Acc. Chem. Res. 49, 1379-1388 (2016)

24. Mereyala, H. B., Hotha, S. \& Gurjar, M. K. Synthesis of pentaarabinofuranosyl structure motif A of Mycobacterium tuberculosis. J. Chem. Soc. Chem. Commun. 685-686 (1998)

25. D'Souza, F. W. \& Lowary, T. L. The first total synthesis of a highly branched arabinofuranosyl hexasaccharide found at the nonreducing termini of mycobacterial arabinogalactan and lipoarabinomannan. Org. Lett. 2, 1493-1495 (2000).

26. Completo, G. C. \& Lowary, T. L. Synthesis of galactofuranose-containing acceptor substrates for mycobacterial galactofuranosyltransferases. J. Org. Chem. 73, 4513-4525 (2008).

27. Wang, S., Meng, X., Huang, W. \& Yang, J.-S. Influence of silyl protections on the anomeric reactivity of galactofuranosyl thioglycosides and application of the silylated thiogalactofuranosides to one-pot synthesis of diverse $\beta$-D-oligogalactofuranosides. J. Org. Chem. 79, 10203-10217 (2014).

28. Kandasamy, J., Hurevich, M. \& Seeberger, P. H. Automated solid phase synthesis of oligoarabinofuranosides. Chem. Commun. 49, 4453-4455 (2013).

29. Huang, X., Huang, L., Wang, H. \& Ye, X.-S. Iterative one-pot synthesis of oligosaccharides. Angew. Chem. Int. Ed. 43, 5221-5224 (2004).

30. Liang, X.-Y., Deng, L.-M., Liu, X. \& Yang, J.-S. Efficient one-pot syntheses of $\alpha$-D-arabinofuranosyl tri- and tetrasaccharides present in cell wall polysaccharide of Mycobacterium tuberculosis. Tetrahedron 66, 87-93 (2010)

31. Ishiwata, A., Akao, H. \& Ito, Y. Stereoselective synthesis of a fragment of mycobacterial arabinan. Org. Lett. 8, 5525-5528 (2006).

32. Gadikota, R. R., Callam, C. S., Wagner, T., Fraino, B. D. \& Lowary, T. L. 2,3-Anhydro sugars in glycoside bond synthesis. Highly stereoselective syntheses of oligosaccharides containing $\alpha$ - and $\beta$-arabinofuranosyl linkages. J. Am. Chem. Soc. 125, 4155-4165 (2003).

33. Lee, Y. J., Lee, K., Jung, E. H., Jeon, H. B. \& Kim, K. S. Acceptor-dependent stereoselective glycosylation: $2^{\prime}$-CB glycoside-mediated direct $\beta$-Darabinofuranosylation and efficient synthesis of the octaarabinofuranoside in mycobacterial cell wall. Org. Lett. 7, 3263-3266 (2005).

34. Zhu, X., Kawatkar, S., Rao, Y. \& Boons, G.-J. Practical approach for the stereoselective introduction of $\beta$-arabinofuranosides. J. Am. Chem. Soc. 128, 11948-11957 (2006)

35. Imamura, A. \& Lowary, T. L. $\beta$-Selective arabinofuranosylation using a 2,3-O-xylylene-protected donor. Org. Lett. 12, 3686-3689 (2010).

36. Thadke, S. A., Mishra, B. \& Hotha, S. Facile synthesis of $\beta$ - and $\alpha$-arabinofuranosides and application to cell wall motifs of M. tuberculosis. Org. Lett. 15, 2466-2469 (2013)

37. Liu, Q.-W., Bin, H.-C. \& Yang, J.-S. $\beta$-Arabinofuranosylation using 5-O-(2-quinolinecarbonyl) substituted ethyl thioglycoside donors. Org. Lett. 15, 3974-3977 (2013)
38. Crich, D., Pedersen, C. M., Bowers, A. A. \& Wink, D. J. On the use of 3,5-O-benzylidene and 3,5-O-(di-tert-butylsilylene)-2-O-benzylarabinothiofuranosides and their sulfoxides as glycosyl donors for the synthesis of $\beta$-arabinofuranosides: importance of the activation method. J. Org. Chem. 72, 1553-1565 (2007).

39. Mizutani, K., Kasai, R., Nakamura, M. \& Tanaka, O. N.M.R. spectral study of $\alpha$ - and $\beta$-L-arabinofuranosides. Carbohydr. Res. 185, 27-38 (1989).

40. Lee, R. E. B., Li, W., Chatterjee, D. \& Lee, R. E. Rapid structure characterization of the arabinogalactan and lipoarabinomannan in live mycobacterial cells using $2 \mathrm{D}$ and 3D HR-MAS NMR: structural changes in the arabinan due to ethambutol treatment and gene mutation are observed. Glycobiology $\mathbf{1 5}$ 139-151 (2005).

41. Konradsson, P., Udodong, U. E. \& Fraser-Reid, B. Iodonium promoted reactions of disarmed thioglycosides. Tetrahedron Lett. 31, 4313-4316 (1990).

42. Vwneman, G. H., van Leeuwen, S. H. \& van Boom, J. H. Iodonium ion promoted reactions at the anomeric centre. II. An efficient thioglycoside mediated approach toward the formation of 1,2-trans linked glycosides and glycosidic esters. Tetrahedron Lett. 31, 1331-1334 (1990).

43. Maity, S. K., Basu, N. \& Ghosh, R. Efficient activation of thioglycosides with $N$-(p-methylphenylthio)- $\varepsilon$-caprolactam-TMSOTf. Carbohydr. Res. 354, 40-48 (2012).

44. Marra, A., Mallet, J.-M., Amatore, C. \& Sinä̈, P. Glycosylation using a one-electron-transfer homogeneous reagent: a novel and efficient synthesis of $\beta$-linked disaccharides. Synlett 572-574 (1990).

45. Goswami, M., Ellern, A. \& Pohl, N. L. B. Bismuth(V)-mediated thioglycoside activation. Angew. Chem. Int. Ed. 52, 8441-8445 (2013).

46. Crich, D. \& Smith, M. 1-Benzenesulfinyl piperidine/trifluoromethanesulfonic anhydride: a potent combination of shelf-stable reagents for the low-temperature conversion of thioglycosides to glycosyl triflates and for the formation of diverse glycosidic linkages. J. Am. Chem. Soc. 123, 9015-9020 (2001).

47. Codée, J. D. C. et al. $\mathrm{Ph}_{2} \mathrm{SO} / \mathrm{Tf}_{2} \mathrm{O}$ : a powerful promotor system in chemoselective glycosylations using thioglycosides. Org. Lett. 5, 1519-1522 (2003).

48. Wang, C., Wang, H., Huang, X., Zhang, L.-H. \& Ye, X.-S. Benzenesulfinyl morpholine: a new promoter for one-pot oligosaccharide synthesis using thioglycosides by pre-activation strategy. Synlett 2846-2850 (2006).

\section{Acknowledgements}

This work was financially supported by the grants from the National Natural Science Foundation of China (21232002) and the Ministry of Science and Technology of China (2013CB910700, 2012CB822100). We thank Professor Qin Li and Professor Lijun Zhong at Peking University Health Science Center for their helpful assistance in analysis of glycan structures.

\section{Author contributions}

D.-C.X. and X.-S.Y. conceived the research. Y.W., D.-C.X. and X.-S.Y. designed the experiments. Y.W. performed all the experiments. S.-C.C. and Y.-S.W. synthesized some building blocks. Y.W., D.-C.X. and X.-S.Y. analyzed the data. Y.W. and X.-S.Y. wrote the manuscript. X.-S.Y. supervised the project.

\section{Additional information}

Supplementary Information accompanies this paper at http://www.nature.com/ naturecommunications

Competing interests: The authors declare no competing financial interests.

Reprints and permission information is available online at http://npg.nature.com/ reprintsandpermissions/

How to cite this article: $\mathrm{Wu}, \mathrm{Y}$. et al. Total synthesis of mycobacterial arabinogalactan containing 92 monosaccharide units. Nat. Commun. 8, 14851 doi: 10.1038/ncomms14851 (2017).

Publisher's note: Springer Nature remains neutral with regard to jurisdictional claims in published maps and institutional affiliations.

This work is licensed under a Creative Commons Attribution 4.0 International License. The images or other third party material in this article are included in the article's Creative Commons license, unless indicated otherwise in the credit line; if the material is not included under the Creative Commons license, users will need to obtain permission from the license holder to reproduce the material. To view a copy of this license, visit http://creativecommons.org/licenses/by/4.0/ 